\title{
Nutritional study of some food coloring agents on experimental rats
}

\author{
Wagih Ahmad El-Malky, Ghada Mahmoud Khiralla, Safaa Ahmad Salem \\ Division of Medical Foods, National Organization for Drug Control and Research (NODCAR), 6-7, AboHazem St, Pyramids, Giza, Egypt
}

Email address:

gkhiralla@yahoo.com (G. M. Khiralla)

\section{To cite this article:}

Wagih Ahmad El-Malky, Ghada Mahmoud Khiralla, Safaa Ahmad Salem. Nutritional Study of Some Food Coloring Agents on Experimental Rats. International Journal of Nutrition and Food Sciences. Vol. 3, No. 6, 2014, pp. 538-544. doi: 10.11648/j.ijnfs.20140306.18

\begin{abstract}
This study was designed to recognize the biochemical and histological alterations in the liver and kidney of male rats due to daily oral intake (for 8 weeks) of beet and curcumin extracts as natural red and yellow color, edicol erythrosine and sunset yellow as recommended synthetic colors and two unknown commercial coloring agents (red and yellow). The effect of admissible daily intake (ADI) and overdose (5 times) of the synthetic recommended and commercial colors was also investigated. Compared with the control group, the GBW \% of rats indicated significant $(p<0.05)$ increase in all studied groups except that given the natural beet extract and that given ADI of edicol erythrosine. No significant differences were detected in the relative kidney weights between groups. Rats that administrated overdose of the studied synthetic colors showed significant increase in the lipid profile of blood including total cholesterol, low density lipoproteins (LDL), high density lipoproteins (HDL). The obtained histopathological changes in liver and kidney of rats administrated overdose of colorants were associated with elevation of urea, creatinine, alanine aminotransferase (ALT) and aspartate aminotransferase (AST), which were strictly related to the injury of kidney and liver functions. The present study demonstrated that beet extract could be used as alternative natural red colorant, whereas curcumin extract need additional long-term studies because of the elevation in urea and AST levels in addition to massive aggregative of inflammatory cells infiltration in the portal area of liver of rats administrated the $7.87 \mathrm{mg}$ curcumin $/ \mathrm{Kg}$ BW. Also, the present study sheds light on the nutritional hazards in the liver and kidney due to the uncontrolled use of synthetic color.
\end{abstract}

Keywords: Beet, Curcumin, Liver, Kidney, Erythrosine, Sunset Yellow

\section{Introduction}

Color is an essential characteristic criterion for food choice. Colorants play a considerable role for improving the aesthetic appeal of food. According to the FDA's regulatory definition, colorants are classified in two classes; the certified (synthetic) color additives, and the color additives excepted from certified (natural) [1]. The total world color production is estimated to be 8 million tons per year [2].

In Egypt, there has been a sharp increase in the use of synthetic food colorants in the past few years and additionally there is an uncontrolled use of synthetic color particularly in food mostly consumed by children [3]. More attention must be focused on the physiological and pathological effects of color additives [4]. Worldwide, the use of colors in food faced with controversy, especially in children nutrition when added to food at high doses [5].

Erythrosine and sunset yellow are widely used in food industry, pharmaceutical and cosmetics as red and yellow coloring agents, respectively. They are permitted by regulatory agencies of many countries [5-6]. Several negative effects of coloring agents have been reported in previous studies, where they have been demonstrated as a causal agents of certain damages in different organs of the experimental animals, i.e in liver and kidney [7]. Recently, European Food Safety Authority (EFSA) suggested re-evaluating the use of some colorants in food such as erythrosine [8].

Although artificial colorants have a long history of use, consumers have increasingly begun to consider synthetic colorants undesirable. Consequently, there has been increased effort to discover new natural alternatives [9-10].

Therefore, the aim of the present work is to study the effect of different coloring agents (natural and synthetic) on 
the lipid profile and liver and kidney functions of rats due to oral intake of the ADI and overdose. Changes in liver and kidney weight in addition to the gain of body weight are also considered.

\section{Materials and Methods}

\subsection{Chemicals}

Six different coloring agents were used in the present study. i) Two natural coloring agents extracted from beet and curcumin as natural red and yellow color, respectively ii) Two recommended coloring agents; edicol erythrosine \#36003 and sunset yellow \#1899 (purchased from Luna Co. for industrial investments, S.A.E, Egypt) and iii) two unknown coloring agents (yellow and red) commercially used in the local market.

\subsection{Preparation of Natural Coloring Agents}

Fresh Beetroots (Beta vulgaris var. rubra) were purchased from the local market, Giza, Egypt. Beetroots were washed, sliced and dried at $50^{\circ} \mathrm{C}$ for $12 \mathrm{~h}$ (to reach about $10 \%$ moisture content; dry basis). Dried slices were ground into powder in an electric blender. Curcumin (Curcumin longa) was purchased in a powder form the local market. Beet and curcumin extracts were prepared by adding $200 \mathrm{ml}$ ethanol (70\%) to $100 \mathrm{~g}$ dried powder. The mixture was shacked at room temperature for $2 \mathrm{~h}$ and then filtered through the Whatman No. 1 filter paper (Whatman International Ltd., Maidstone, UK). The extraction procedure was repeated 3 times. The filtrates were collected and the ethanol was evaporated at $50^{\circ} \mathrm{C}$. Dried color extract was powdered and used as natural coloring agents.

\subsection{Animals and Treatments}

Sixty six male Albino strain rats were obtained from National Organization Drug Control and Research (NODCAR), Giza, Egypt. Adult animals (120 - 150 \pm 2 g, 10 weeks age). The animals were housed in separate stainless steel cages under controlled conditions at constant temperature $\left(24^{0} \mathrm{C}\right)$ and given free access to food and water throughout the experimental period ( 8 weeks). After adaptation period (15 days) rats were divided into eleven groups $(n=6)$ and fed on basal diet ( $10 \%$ casein, $10 \%$ corn oil, $5 \%$ cellulose, $1 \%$ vitamin mixture, $4 \%$ salt mixture, $70 \%$ corn starch (Lana Peter and Pearson, 1971) for 8 weeks. Rates were treated daily with one $\mathrm{ml}$ of color solution (containing the tested concentration of rat dose comparing human dose / $\mathrm{Kg}$ body weight) by oral stomach tube as follows:

BE-Group: administrated beet extract as a natural red color (0.31 mg beet powder).

NEE-Group: administrated Admissible Daily Intake (ADI) of edicol erythrosine) \#36003 (0.06 mg).

OEE-Group: administrated overdose of edicol erythrosine) \#36003 (0.31 mg).

NCR-Group: administrated ADI of an unknown commercial red color $(0.06 \mathrm{mg})$.

OCR-Group: administrated overdose of a unknown commercial red color $(0.31 \mathrm{mg})$.

CE-Group: administrated curcumin extract as a natural yellow color ( $7.87 \mathrm{mg}$ curcumin powder).

NSS-Group: administrated ADI of sunset yellow \#1899 (1.57 mg).

OSS-Group: administrated overdose of sunset yellow \#1899 (7.87 mg).

NCY-Group: administrated ADI of an unknown commercial yellow color $(1.57 \mathrm{mg})$.

OCY-Group: administrated overdose of an unknown commercial yellow color $(7.87 \mathrm{mg})$.

\subsection{Gain of Body Weight}

Rats were observed daily for the appearance of any symptoms of discomfort that might be related to study treatments. Body weight (BW) of the rats was recorded at the beginning of the experiment and 4 and 8 weeks after treatment with coloring agents. At the end of experiment period (8 weeks), the percentage of gain weight was expressed [(final weight - beginning weight) / beginning weight] $\times 100$.

\subsection{Liver and Kidney Weight}

At the end of the experimental period, rats were weighted and killed by diethyl ether. Liver and kidney were cut off, washed in ice-cooled saline solution $0.15 \mathrm{M} \mathrm{KCl}$ to remove blood, weighed and stored on ice until analyzed [11]. The liver and kidney weight percentage were calculated as a percentage from the body weight on the sixty day.

\subsection{Biochemical Assay}

At the beginning and end of experimental period, blood samples were collected from the eye plexuses of animals by a fine capillary glass tubes and placed immediately on ice. Blood serum samples were collected into dry clean centrifuge tubes; the serum was separated after centrifugation for $10 \mathrm{~min}$ at 3000 $\operatorname{rpm}(1500 \mathrm{xg})$ and kept at $-20{ }^{\circ} \mathrm{C}$ until analysis. The following biochemical parameters were estimated by test reagent kits (Biodiagnostics, Egypt) mentioned below. Total protein (TP) [12], urea, [13], creatinine, [14], total cholesterol (TC), low density lipoproteins (LDL), high density lipoproteins (HDL), glucose, alanine aminotransferase (ALT; EC 2.6.1.2) and aspartate aminotransferase (AST; EC 2.6.1.1) [15].

\subsection{Histopatholagical Assessment}

Autopsy samples were taken from the liver and kidney of rats in different groups and fixed in $10 \%$ normal saline for $24 \mathrm{~h}$. Washing was done in tap water then serial dilutions of alcohol (methyl, ethyl and absolute ethyl) were used for dehydration. Specimens were cleared in xylene and embedded in paraffin at $56{ }^{\circ} \mathrm{C}$ in hot air oven for $24 \mathrm{~h}$. Paraffin bees wax tissue blocks were prepared for sectioning at 4 microns thickness by sledge microtome. The obtained tissue sections were collected on glass slides, deparaffinized, stained by hematoxylin \& eosin stain for routine examination through the light electric microscope [16]. 


\subsection{Statistical Analysis}

All values are means $\pm \mathrm{SE}$ obtained from six animals. Data were analyzed with SAS software (SAS Institute, Cary, N.C.) using SAS analysis of variance (PROC ANOVA). Significant differences between means were determined by Tukey's multiple range test $(P=0.05)$.

\section{Results and Discussion}

\subsection{Body Weight and the Gain in Body Weight}

Body weight $(\mathrm{BW})$ and the percentage of gain in body weight (GBW \%) were expressed and presented in Table 1. At the initial point, there is no significant differences in BW were recorded between the studied groups. BW of all tested groups was significantly increased by increasing the experiment periods (4weeks and 8 weeks). Compared with the control group at the end of the experiment, significant $(p<0.05)$ increases were recorded in the $\mathrm{BW}$ of the rats given overdose of the commercial red (OCR-group) and yellow (OCY-group) colors followed by that administrated overdose of edicol erythrosine (Table 1). The other studied groups showed slight increase in BW compared with the control group after 8 weeks.

Table 1. Changes in body weight* of rats given food coloring agents

\begin{tabular}{lllll}
\hline Groups & Initial & 4 weeks & 8 weeks & GBW \% \\
\hline Control & $139 \pm 10^{\mathrm{c}, \mathrm{A}}$ & $205 \pm 10^{\mathrm{b}, \mathrm{C}}$ & $245 \pm 19^{\mathrm{a}, \mathrm{E}}$ & $76 \pm 1^{\mathrm{c}}$ \\
BE & $147 \pm 12^{\mathrm{c}, \mathrm{A}}$ & $212 \pm 12^{\mathrm{b}, \mathrm{A}}$ & $258 \pm 13^{\mathrm{a}, \mathrm{CDE}}$ & $76 \pm 2^{\mathrm{c}}$ \\
NEE & $140 \pm 11^{\mathrm{c}, \mathrm{A}}$ & $237 \pm 37^{\mathrm{b}, \mathrm{A}}$ & $250 \pm 17^{\mathrm{a}, \mathrm{CDE}}$ & $79 \pm 6^{\mathrm{c}}$ \\
OEE & $146 \pm 20^{\mathrm{c}, \mathrm{A}}$ & $225 \pm 18^{\mathrm{b}, \mathrm{A}}$ & $276 \pm 13^{\mathrm{a}, \mathrm{B}}$ & $89 \pm 9^{\mathrm{b}}$ \\
NCR & $135 \pm 8^{\mathrm{c}, \mathrm{A}}$ & $223 \pm 15^{\mathrm{b}, \mathrm{A}}$ & $254 \pm 16^{\mathrm{a}, \mathrm{CDE}}$ & $88 \pm 7^{\mathrm{b}}$ \\
OCR & $136 \pm 7^{\mathrm{c}, \mathrm{A}}$ & $222 \pm 14^{\mathrm{b}, \mathrm{A}}$ & $292 \pm 11^{\mathrm{a}, \mathrm{A}}$ & $114 \pm 10^{\mathrm{a}}$ \\
CE & $118 \pm 14^{\mathrm{c}, \mathrm{A}}$ & $195 \pm 14^{\mathrm{b}, \mathrm{A}}$ & $248 \pm 19^{\mathrm{a}, \mathrm{CDE}}$ & $110 \pm 8^{\mathrm{a}}$ \\
NSS & $140 \pm 12^{\mathrm{c}, \mathrm{A}}$ & $202 \pm 30^{\mathrm{b}, \mathrm{A}}$ & $263 \pm 10^{\mathrm{a}, \mathrm{BCD}}$ & $110 \pm 7^{\mathrm{a}}$ \\
OSS & $144 \pm 17^{\mathrm{c}, \mathrm{A}}$ & $215 \pm 14^{\mathrm{b}, \mathrm{A}}$ & $266 \pm 16^{\mathrm{a}, \mathrm{BC}}$ & $85 \pm 5^{\mathrm{b}}$ \\
NCY & $139 \pm 14^{\mathrm{c}, \mathrm{A}}$ & $217 \pm 14^{\mathrm{b}, \mathrm{A}}$ & $260 \pm 16^{\mathrm{a}, \mathrm{BCD}}$ & $87 \pm 8^{\mathrm{b}}$ \\
OCY & $145 \pm 17^{\mathrm{c}, \mathrm{A}}$ & $206 \pm 38^{\mathrm{b}, \mathrm{A}}$ & $301 \pm 13^{\mathrm{a}, \mathrm{A}}$ & $107 \pm 4^{\mathrm{a}}$ \\
LSD & 35.65 & 42.93 & 16.637 & \\
\hline
\end{tabular}

BE, Beet extract; NEE, ADI of edicol erythrosine \#36003; OEE, overdose of edicol erythrosine \#36003; NCR, ADI of an unknown commercial red color; OCR, overdose of an unknown commercial red color; CE, curcumin extract; NSS, ADI of sunset yellow \#1899; OSS, overdose of sunset yellow \#1899; NCY, ADI of a commercial yellow color; OCY, overdose of an unknown commercial red color.

* means $(\mathrm{g}) \pm$ standard deviation

Superscripted capital and small letters indicate the statistical significant differences between groups (in the same column) and experimental intervals (in the same row), respectively. $n=6 ; p=0.05$.

Compared with the control group at the end of the experiment, the GBW \% of rats indicated considerable increase in all studied groups except that given the natural beet extract as a natural coloring agent (BE-group) and that given ADI of edicol erythrosine (NEE-group). In accordance with the obtained results, significant reduction $(p<0.05)$ in the gain body weight has been recorded in previous study [17]. A number of studies demonstrate that erythrosine affects the rat thyroid, particularly in males [17-18]. On contrary, other colorants that do not affect the thyroid lead to increase food consumption result in increase gain in body weight [17]. This statement could explain the elevation in the GBW obtained by NSS group, which administrated sunset yellow color.

\subsection{Organ Weights}

Absolute and relative weights of liver and kidney are shown in Table 2. Absolute liver weights of rats in all groups, except CE-group (administrated curcumin extract, $7.87 \mathrm{mg}$ curcumin powder / rat, daily), were significantly $(p<0.05)$ increased compared with the control-group. The relative liver weight of CE-group was significantly decreased, whereas OCR- and OCY-groups (administrated overdose of commercial red and yellow coloring agents, respectively) showed increase in the relative liver weights. On the other hand, there were insignificant differences between relative liver weights of the rats in the other studied groups compared with the control-group. All groups displayed significant difference in the absolute kidney weight compared with the control group; however, no significant differences were detected in the relative kidney weights between groups.

Table 2. Final absolute and relative weights (means $\pm S D$ ) for liver and kidney of rats given food coloring agents

\begin{tabular}{lllll}
\hline \multirow{2}{*}{ Groups } & Liver weight & \multicolumn{3}{c}{ Kidney weight } \\
\cline { 2 - 5 } & Absolute (g) & Relative (\%) & Absolute (g) & Relative (\%) \\
\hline Control & $6.65 \pm 0.21$ & $3.01 \pm 0.15$ & $1.13 \pm 0.04$ & $0.51 \pm 0.02$ \\
BE & $7.90 \pm 0.14^{*}$ & $2.93 \pm 0.05$ & $1.40 \pm 0.21$ & $0.52 \pm 0.08$ \\
NEE & $8.35 \pm 0.35^{*}$ & $3.15 \pm 0.13$ & $1.43 \pm 0.18$ & $0.54 \pm 0.07$ \\
OEE & $9.65 \pm 0.49^{*}$ & $3.28 \pm 0.17$ & $1.65 \pm 0.07^{*}$ & $0.56 \pm 0.02$ \\
NCR & $8.00 \pm 0.42$ & $2.90 \pm 0.15$ & $1.45 \pm 0.07^{*}$ & $0.53 \pm 0.03$ \\
OCR & $9.25 \pm 0.07^{*}$ & $3.33 \pm 0.03^{*}$ & $1.70 \pm 0.14^{*}$ & $0.61 \pm 0.05$ \\
CE & $6.40 \pm 0.04$ & $2.58 \pm 0.03^{*}$ & $1.30 \pm 0.01^{*}$ & $0.52 \pm 0.03$ \\
NSS & $8.00 \pm 0.28^{*}$ & $2.94 \pm 0.10$ & $1.53 \pm 0.04^{*}$ & $0.56 \pm 0.01$ \\
OSS & $8.70 \pm 0.14^{*}$ & $3.27 \pm 0.05$ & $1.53 \pm 0.11^{*}$ & $0.57 \pm 0.04$ \\
NCY & $8.00 \pm 0.28^{*}$ & $2.86 \pm 0.10$ & $1.53 \pm 0.11^{*}$ & $0.54 \pm 0.04$ \\
OCY & $9.60 \pm 0.14^{*}$ & $3.64 \pm 0.05^{*}$ & $1.58 \pm 0.11^{*}$ & $0.60 \pm 0.04$ \\
\hline
\end{tabular}

Abbreviations of groups are described in Table 1.

\# Calculated as a ratio from the body weight of each group after 8 weeks (Table 1)

* Significantly different from the control group in the same column. $n=6$; $p$ $=0.05$.

\subsection{Biochemical Parameters}

The changes in lipid profile and blood glucose due to oral intake of different coloring agents were presented in Table 3. Little changes in the total cholesterol levels of the rats in NSS and NCY groups were observed compared with the initial and control group ( $\mathrm{LSD}=8$, Table 1). However, rats that administrated overdose of the studied synthetic colors (OEE, OCR, OSS and OCY groups) showed significant increase in the blood cholesterol. The highest value of total cholesterol $(132.93 \mathrm{mg} / \mathrm{dl})$ was recorded by OCY group. The changes in the lipid profile obtained in the present study were in agreement with those mentioned previously by Sarhan el al., [19]. They mentioned that significant changes have occurred in the level of serum total lipids and total cholesterol of rats treated with sunset yellow. It is well known that the increase in cholesterol concentration is an indication of membrane 
structure and function disruption, thus influence its fluidity, permeability, activity of associated enzymes and transport system [19].

Table 3. Effect of food coloring agents on lipid profile and glucose

\begin{tabular}{lllll}
\hline Groups & $\begin{array}{l}\text { Total cholesterol } \\
(\mathbf{m g} / \mathbf{d l})^{*}\end{array}$ & $\begin{array}{l}\text { HDL } \\
(\mathbf{m g} / \mathbf{d l})^{*}\end{array}$ & $\begin{array}{l}\text { LDL } \\
(\mathbf{m g} / \mathbf{d l})^{*}\end{array}$ & $\begin{array}{l}\text { Glucose } \\
(\mathbf{m g} / \mathbf{d l})^{*}\end{array}$ \\
\hline Initial & $90.1 \pm 0.86^{\mathrm{f}}$ & $59.7 \pm 3.8^{\mathrm{bc}}$ & $30.4 \pm 0.42^{\mathrm{g}}$ & $108.7 \pm 2.0^{\mathrm{a}}$ \\
Control & $91.5 \pm 0.5^{\text {ef }}$ & $56.2 \pm 1.2^{\mathrm{bcd}}$ & $35.3 \pm 1.43^{\mathrm{f}}$ & $125.9 \pm 2.0^{\mathrm{a}}$ \\
BE & $90.0 \pm 0.5^{\mathrm{f}}$ & $51.6 \pm 1.4^{\text {cd }}$ & $38.4 \pm 0.6^{\mathrm{cd}}$ & $123.3 \pm 1.0^{\mathrm{a}}$ \\
NEE & $100.3 \pm 0.2^{\text {cd }}$ & $55.3 \pm 0.4^{\mathrm{bcd}}$ & $45.0 \pm 0.6^{\text {cde }}$ & $122.3 \pm 8.0^{\mathrm{a}}$ \\
OEE & $129.4 \pm 0.1^{\mathrm{a}}$ & $61.6 \pm 1.8^{\mathrm{b}}$ & $67.8 \pm 1.5^{\mathrm{a}}$ & $128.0 \pm 1.0^{\mathrm{a}}$ \\
NCR & $104.9 \pm 0.9^{\mathrm{bc}}$ & $61.8 \pm 4.3^{\mathrm{b}}$ & $43.1 \pm 1.5^{\text {de }}$ & $124.8 \pm 6.0^{\mathrm{a}}$ \\
OCR & $126.7 \pm 1.1^{\mathrm{a}}$ & $58.8 \pm 3.8^{\mathrm{bc}}$ & $67.9 \pm 3.2^{\mathrm{a}}$ & $128.3 \pm 1.0^{\mathrm{a}}$ \\
CE & $92.8 \pm 1.8^{\text {def }}$ & $49.5 \pm 5.8^{\mathrm{d}}$ & $43.3 \pm 1.2^{\text {de }}$ & $82.9 \pm 2.0^{\mathrm{b}}$ \\
NSS & $97.7 \pm 0.4^{\text {cdef }}$ & $54.6 \pm 1.4^{\mathrm{bcd}}$ & $43.1 \pm 0.5^{\text {de }}$ & $114.2 \pm 3.1^{\mathrm{a}}$ \\
OSS & $110.6 \pm 0.9^{\mathrm{b}}$ & $62.2 \pm 4.3^{\mathrm{b}}$ & $48.4 \pm 0.8^{\mathrm{c}}$ & $123.9 \pm 4.0^{\mathrm{a}}$ \\
NCY & $99.4 \pm 0.6^{\text {cde }}$ & $58.0 \pm 2.2^{\mathrm{bc}}$ & $41.4 \pm 0.5^{\mathrm{e}}$ & $117.3 \pm 5.8^{\mathrm{a}}$ \\
OCY & $132.9 \pm 0.4^{\mathrm{a}}$ & $70.5 \pm 3.8^{\mathrm{a}}$ & $62.4 \pm 2.4^{\mathrm{b}}$ & $123.8 \pm 7.0^{\mathrm{a}}$ \\
LSD & 8.0 & 8.1 & 3.7 & 19.6 \\
\hline
\end{tabular}

Abbreviations of groups are described in Table 1.

* means $(\mathrm{g}) \pm$ standard deviation

Superscripted small letters indicate the statistical significant differences between groups (in the same column). $n=6 ; p=0.05$.

On the other hand, no significant changes in the total cholesterol level of the rats of BE and CE groups were noticed compared with the initial or control group. This finding indicated that administrating beet or curcumin extract led to maintaining the lipid profile (total cholesterol, HDL and LDL) close to the initial and control group. This finding could be explained by the presence of polyphenolic compounds in these natural extracts which have been previously reported to protect lipids, blood and body fluids against the attack reactive oxygen species like superoxide, peroxide, and hydroxyl radicals [19-20]. Moreover, one of the lipid-lowering mechanisms of the curcumin is the up-regulation of the expression of LDL receptor in mouse macrophages followed by lowering cholesterol level in plasma [21]. Concerning glucose level, no significant difference between all groups of rats in glucose value, except CE- group, which showed low glucose level $(82.9 \mathrm{mg} / \mathrm{dl})$ compared with other studied groups $(108.7-128.3 \mathrm{mg} / \mathrm{dl})$.

The effect of food coloring agents on some functions of liver and kidney were measured and showed in Table 3. All determined liver and kidney functions of the initial and control group were in the normal range of these parameters in rats. Rats administrated overdose of all studied colors (OEE, OCR, OSS and OCY) showed high significant values $(p<0.05)$ compared with the other groups. Moreover, NCR group showed high urea level, whereas NSS and NCY groups displayed high AST value compared with control group. In agreement with these results, Helal et al., [1] and Sarhan et al., [19] stated that sunset yellow led to increase urea, creatinine, ALT and AST, which were strictly associated to the injury of renal and liver functions. Concerning with the natural colors used in the present study, insignificant difference was noticed between control group and the rats administrated beet extract as a natural red color (BE group). These finding demonstrated the protective effect of beet extract elevation of liver and kidney functions [19]. However, decrease in total protein level and elevation of urea and AST were recorded in CE-group, which administrated curcumin extract. In a previous study, administrating curcumin extract for 4 weeks led to increase urea and AST level in serum of treated rats [1].

\subsection{Histological Changes of Liver}

The histopathological lesions in livers of rats fed on beet extract, recommended and commercial red colors were presented in Fig. 1. No histopathological alteration was recorded in the liver of rats in control-group and in the rats administrated beet extract, ADI of the recommended and commercial red color. However, congestion was observed in the central vein of the rats treated with overdose of edicol erythrosine (OEE-group, Fig 1, D). Moreover, mild dilatation in the central veins and sinusoids were observed when rats were treated with overdose of the tested commercial red color (OCR-group, Fig. 1, F).

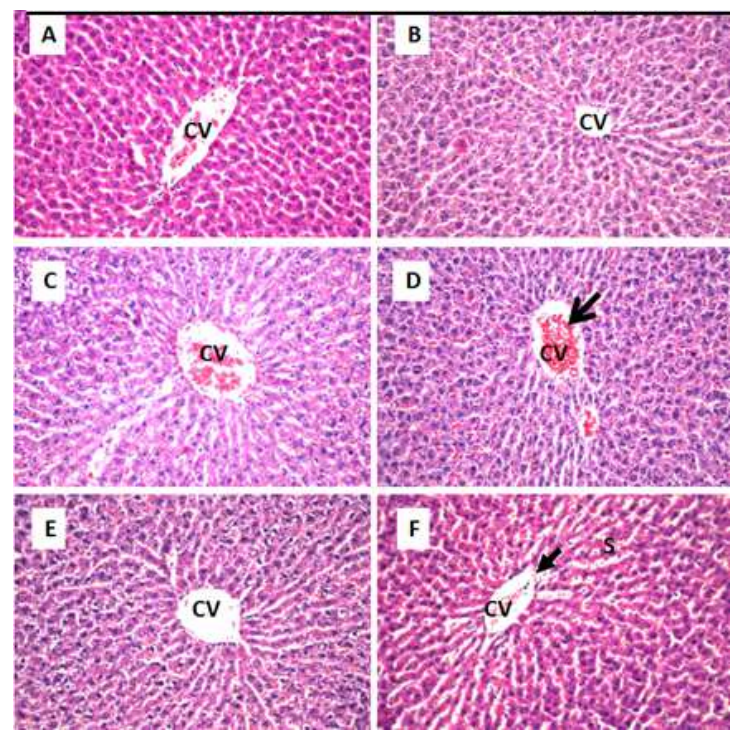

Figure 1. Histopathological changes in liver of the adult rats 8 weeks after daily oral intake of beet extract (B); ADI of edicol erythrosine \#36003 (C); overdose of edicol erythrosine \#36003 (D); ADI of an unknown commercial red color (E); overdose of an unknown commercial red color $(F)$. Control $(A)$ and the other groups displayed normal architecture. (H\&E, X40). Congestion (open arrow), mild dilatation (closed arrow) and sinusoids (S) were observed in the central vein in rats treated with overdose of the recommended $(D)$ and commercial $(F)$ red colors.

The histopathological lesions in livers of rats fed on curcumin extract, recommended and commercial yellow colors were presented in Fig. 2. Massive aggregative of inflammatory cells infiltration was noticed in the portal area of the liver of rats administrated the $7.87 \mathrm{mg}$ curcumin powder/Kg BW, daily (CE-group, Fig. 2, B). This alteration may be responsible for the elevation of AST recorded in the present study. Dilatation and congestion in central vein of rats administrated overdose of a commercial yellow color was noticed (OCY-group, Fig. 2, F). On the other hand, control-group and the other tested groups displayed normal liver architecture. 


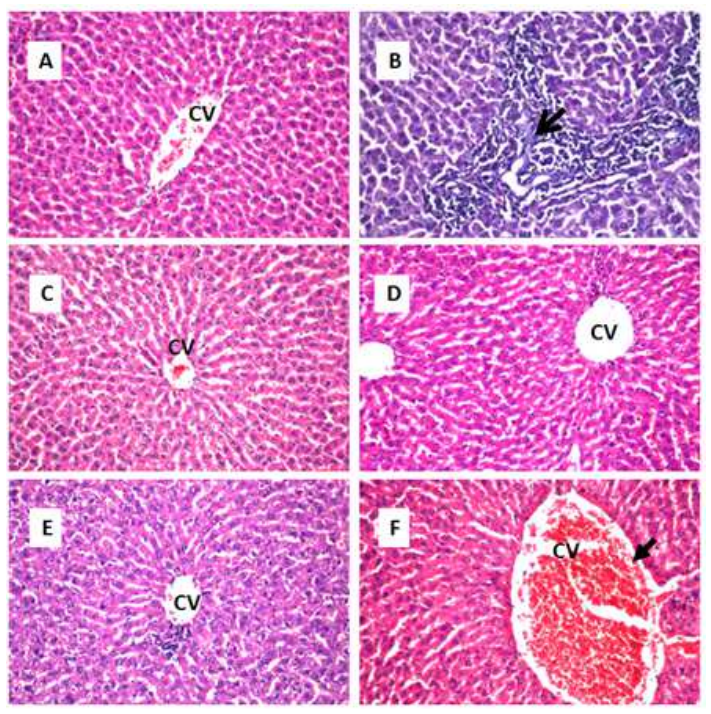

Figure 2. Histopathological changes in liver of the adult rats 8 weeks after daily oral intake of curcumin extract (B); ADI of sunset yellow \#1899 (C); overdose of sunset yellow \#1899 (D); ADI of an unknown commercial yellow color (E); overdose of an unknown commercial yellow color $(F)$. Control $(A)$ and the other groups displayed normal architecture. (H\&E, X40) Massive aggregative of inflammatory cells infiltration (open arrow) was noticed in the portal area of the liver of rats administrated the natural yellow color (B). Dilatation and congestion in central vein (closed arrow) of rats administrated overdose of a commercial yellow color was noticed $(F)$

The liver is the main target organ of acute toxicity when exposed to the foreign substances, toxins, chemicals and plant extracts. When these substances are absorbed in intestines they are metabolized to other compounds which may or may not be hepatotoxic to the rats [22]. In the present study, the liver histology revealed evidence of different changes in rats fed on curcumin or overdose of the recommended and commercial synthetic colors. This was further demonstrated by the increase in liver enzyme activities in these groups (Table 4).

Table 4. Effect of food coloring agents on some functions of liver and kidney

\begin{tabular}{llllll}
\hline Groups & TP $(\mathbf{g} / \mathbf{d l})$ & $\begin{array}{l}\text { Urea } \\
(\mathbf{m g} / \mathbf{d l})\end{array}$ & $\begin{array}{l}\text { Creatinine } \\
(\mathbf{m g} / \mathbf{d l})\end{array}$ & $\begin{array}{l}\text { ALT } \\
(\mathbf{I U} / \mathbf{l})\end{array}$ & $\begin{array}{l}\text { AST } \\
(\mathbf{I U} / \mathbf{l})\end{array}$ \\
\hline Initial & $5.9 \pm 0.5^{\mathrm{fg}}$ & $15.6 \pm 2.1^{\mathrm{d}}$ & $0.9 \pm 0.1^{\mathrm{c}}$ & $26.0 \pm 1.7^{\mathrm{c}}$ & $42.3 \pm 2.9^{\mathrm{d}}$ \\
Control & $6.5 \pm 0.2^{\text {def }}$ & $15.5 \pm 0.3^{\mathrm{d}}$ & $0.9 \pm 0.1^{\mathrm{abc}}$ & $43.7 \pm 1.5^{\mathrm{b}}$ & $46.3 \pm 1.5^{\mathrm{d}}$ \\
$\mathrm{BE}$ & $6.4 \pm 0.5^{\mathrm{efg}}$ & $15.9 \pm 0.6^{\mathrm{d}}$ & $0.9 \pm 0.1^{\mathrm{abc}}$ & $42.3 \pm 0.6^{\mathrm{b}}$ & $44.0 \pm 1.4^{\mathrm{d}}$ \\
NEE & $7.4 \pm 0.2^{\mathrm{abcd}}$ & $17.0 \pm 0.2^{\mathrm{d}}$ & $0.8 \pm 0.1^{\mathrm{bc}}$ & $45.3 \pm 1.5^{\mathrm{b}}$ & $42.3 \pm 2.2^{\mathrm{d}}$ \\
OEE & $7.9 \pm 0.3^{\mathrm{a}}$ & $19.1 \pm 0.3^{\mathrm{cd}}$ & $1.0 \pm 0.1^{\mathrm{abc}}$ & $58.7 \pm 2.5^{\mathrm{a}}$ & $74.3 \pm 5.5^{\mathrm{b}}$ \\
NCR & $6.5 \pm 0.8^{\text {def }}$ & $18.9 \pm 0.8^{\mathrm{c}}$ & $0.9 \pm 0.3^{\mathrm{abc}}$ & $42.3 \pm 0.6^{\mathrm{b}}$ & $68.5 \pm 7.7^{\mathrm{bc}}$ \\
OCR & $7.9 \pm 0.3^{\mathrm{ab}}$ & $25.8 \pm 3.5^{\mathrm{a}}$ & $1.2 \pm 0.3^{\mathrm{a}}$ & $56.3 \pm 1.5^{\mathrm{a}}$ & $92.0 \pm 2.8^{\mathrm{a}}$ \\
CE & $5.55 \pm 0.17^{\mathrm{g}}$ & $21.2 \pm 1.3^{\mathrm{bc}}$ & $1.1 \pm 0.3^{\mathrm{ab}}$ & $42.7 \pm 1.2^{\mathrm{b}}$ & $71.3 \pm 5.5^{\mathrm{bc}}$ \\
NSS & $7.00 \pm 0.18^{\mathrm{bced}}$ & $18.9 \pm 0.8^{\mathrm{cd}}$ & $1.1 \pm 0.2^{\mathrm{abc}}$ & $44.0 \pm 2.0^{\mathrm{b}}$ & $64.3 \pm 1.8^{\mathrm{c}}$ \\
OSS & $7.80 \pm 0.24^{\mathrm{ab}}$ & $24.2 \pm 0.9^{\mathrm{ab}}$ & $0.9 \pm 0.2^{\mathrm{abc}}$ & $59.0 \pm 1.0^{\mathrm{a}}$ & $88.8 \pm 1.7^{\mathrm{a}}$ \\
NCY & $6.7^{\mathrm{C}} \pm 0.1^{\text {def }}$ & $18.7 \pm 0.6^{\mathrm{cd}}$ & $0.8 \pm 0.05^{\mathrm{abc}}$ & $46.0 \pm 3.6^{\mathrm{b}}$ & $66.0 \pm 5.6^{\mathrm{bc}}$ \\
OCY & $7.5 \pm 0.1^{\mathrm{abc}}$ & $26.8 \pm 2.1^{\mathrm{a}}$ & $0.9 \pm 0.1^{\mathrm{abc}}$ & $59.6 \pm 1.5^{\mathrm{a}}$ & $94.7 \pm 2.2^{\mathrm{a}}$ \\
LSD & 0.88 & 4.22 & 0.43 & 5.22 & 9.82 \\
\hline
\end{tabular}

Abbreviations of groups are described in Table 1.

* means $(\mathrm{g}) \pm$ standard deviation

Superscripted small letters indicate the statistical significant differences between groups (in the same column). $n=6 ; p=0.05$.

\subsection{Histological Changes of Kidney}

The histopathological alterations in kidney of rats fed on beet extract, recommended and commercial red colors were shown in Fig. 3. Different histological lesions have appeared in the kidney of all treated rats at different levels, whereas the control-group displayed normal architecture. Vacuolization in the lining endothelium of the glomerular tufts were recorded in all treated rats.

Moreover, tubules degeneration was appeared in the kidney of rats treated with the ADI or overdose of the tested commercial red color. In the rats treated with overdose of edicol erythrosine (OEE-group), focal lymphoid cells aggregation in the perivascular tissue surrounding the congested blood vessels were noticed (Fig. 3, D).

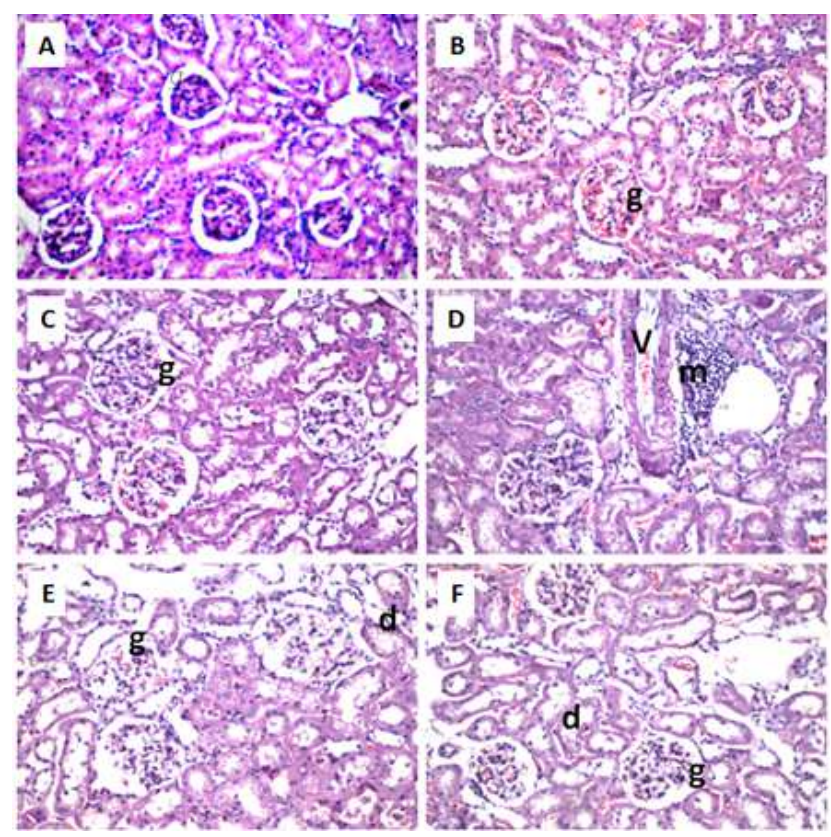

Figure 3. Histopathological changes in kidney of the adult rats 8 weeks after daily oral intake of beet extract (B); ADI of edicol erythrosine \#36003 (C); overdose of edicol erythrosine \#36003 (D); ADI of an unknown commercial red color (E); overdose of an unknown commercial red color (F). Control groups (A) displayed normal architecture. $(H \& E, \quad X 40)$. The histopathological lesions were vacuolization in the lining endothelium of the glomerular tufts (g); focal lymphoid cells aggregation in the perivascular tissue (m) surrounding the congested blood vessels (V) and/or tubules degeneration (d).

The histopathological changes in kidney of rats fed on curcumin extract, recommended and commercial yellow colors were displayed in Fig. 4. Congestion in the cortical blood vessels was demonstrated in the kidney of rats given curcumin extract (CE-group) or ADI of sunset yellow (NSS-group). Vacuolization in the lining endothelium of the glomerular tufts and focal lymphoid cells aggregation in the perivascular tissue were observed in the kidney of rats given overdose of sunset color (OSS-group). The histopathological alterations in kidney of rats observed in the present investigation demonstrated the significant changes that were recorded in kidney function values (Table 4). 


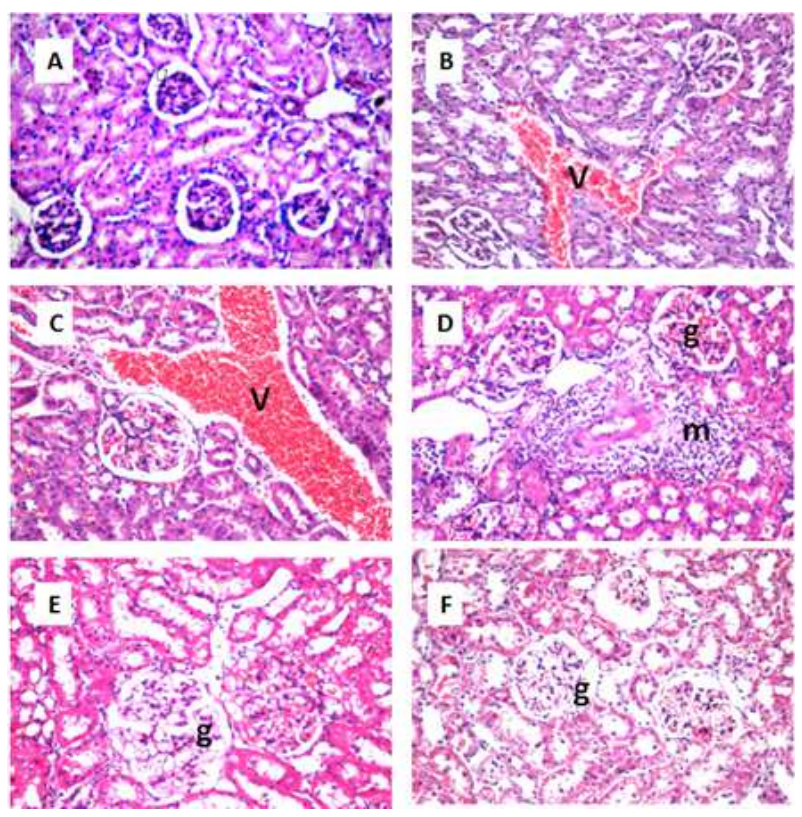

Figure 4. Histopathological changes in kidney of the adult rats 8 weeks after daily oral intake of curcumin extract (B); ADI of sunset yellow \#1899 (C); overdose of sunset yellow \#1899 (D); ADI of an unknown commercial yellow color (E); overdose of an unknown commercial yellow color $(F)$. Control groups (A) displayed normal architecture. (H\&E, X40). The histopathological lesions were vacuolization in the lining endothelium of the glomerular tufts (g); focal lymphoid cells aggregation in the perivascular tissue ( $m$ ) and congestion in the cortical blood vessels $(V)$.

\section{Conclusion}

The results obtained in the present investigation indicated the normal liver and kidney architecture and biochemical parameters when beet extract $(0.31 \mathrm{mg} / \mathrm{kg} \mathrm{BW}$, daily for 8 weeks) was used as a red colorant. These results support the trend of using the natural coloring agents such as beet extract. Most studied parameters were also in the normal range when curcumin extract $(7.87 \mathrm{mg} / \mathrm{kg} \mathrm{BW}$, daily for 8 weeks) was used, except elevation in the urea and AST levels in addition to massive aggregative of inflammatory cells infiltration and congestion in the cortical blood vessels in the liver and kidney, respectively. Although several previous studies have mentioned the safe use of curcumin, the obtained results indicated the necessary of additional long-term studies with changing the dose that will be provided to rats. Moreover, the use of ADI of edicol erythrosine and sunset yellow as recommended synthetic red and yellow colors, respectively, and even the commercial colorants led to obtain acceptable histopathological and biochemical data. However, use of overdose from these colorants led to dramatic alteration in the liver and kidney in addition to disordering in the liver and kidney functions. Therefore, the present study sheds light on the nutritional hazards in the liver and kidney due to the uncontrolled use of synthetic colorants.

\section{Acknowledgements}

The authors would to thanks Dr. Adel Bakeer Kholoussy, Prof. of Pathology, Faculty of Veterinary Medicine, Cairo
University, for his valuable discussions and explanation of the obtained results.

\section{References}

[1] Helal, E.G.E., S.A.M. Zaahkouk, and H.A. Mekkawy, Effect of some food colorants (synthetic and natiral products) of young albino rats. Egypt. J. Hospital Med., 2000. 1: p. 103-113.

[2] Soltan, S.S.A. and M.M.E.M. Shehata, The effects of using color foods of children on immunity properties and liver, kidney on rats. Food and Nutrition Sciences, 2012. 3: p. 897-904.

[3] Salah, S.H., Biochemical studies on some synthetic food colorants. M.Sc. (Blochemistry). Fac. Agric., Cairo Univ. 1994.

[4] Ganong, W.E ,.Review of medical physiology. 15th ed. Lange Medical Book. 1991

[5] Hashem, M.M., et al., Immunological studies on amaranth sun-set yellow and curcumin as food coloring agents in albino rats. Food and Chemical Toxicology, 2010. 48(6): p. 1581-1586.

[6] Lakdawalla, A.A. and M.S. Netrawali, Mutagenicity, comutagenicity, and antimutagenicity of erythrosine (FD and C Red 3), a food dye, in the Ames/Salmonella assay. Mutation Research/Genetic Toxicology, 1988. 204(2): p. 131-139.

[7] Hassan, G.M., Effect of some synthetic coloring additives on dna damage and chromosomal aberration of rats. Arab Journal. Biotechnology, 2009. 13(1): p. 13-24.

[8] (EFSA) European Food Safety Authority, Scientific Opinion on the re-evaluation of Erythrosine (E 127) as a food additive. EFSA Journal, 2011. 9(1): p. 1854.

[9] Socaciu, C., Natural pigments as food colorants. In: Socaciu C, editor. Food colorants: chemical and functional properties. Boca Raton, Fla.: CRC Press. ph. 583-601. 2008.

[10] Dabas, D., et al., A Colored Avocado Seed Extract as a Potential Natural Colorant. Journal of Food Science, 2011. 76(9): p. C1335-C1341.

[11] Waschulewski, I.H. and R.A. Sunde, Effect of dietary methionine on utilization of tissue selenium from dietar selenomethionine for glutathione peroxidase in the rat. J. Nutr., 1988. 118: p. 367-374.

[12] Lowry, O.H., et al., Protein measurement with the Folin Phenol Reagent. J. Bio. Chem., 1951. 193: p. 269-275.

[13] Patton, C.J. and S.R. Crouch, Spectrophotometric and kinetic investigation of the bertha lot reaction for the determination of ammonia. Anal. Chem., 1977. 49: p. 464-469.

[14] Faulkner, W.R. and J.W. King, Fundamentals of Clinical Chemistry, 1st ed., The Alden Press and Kemp Hall Bindery, Oxford, Britain. 1976.

[15] Bergmeyer, H.U. and M. Harder ,A colorimeteric methods of determination of serum glutamic oxaloacetic and glutamic pyruvic transaminase. Clin. Biochem., 1986. 24: p. 28 - 34.

[16] Banchroft, J.D., A. Stevens, and D.R. Turner, Theory and practice of histological techniques. 4 ed. 1996 :Churchil Livingstone, New York, London, San Francisco, Tokyo. 
[17] Borzelleca, J.F. and J.B. Hallagan, Multigeneration study of FD \& C Red No. 3 (erythrosine) in Sprague-Dawley rats. Food Chem Toxicol. , 1990. 28(12): p. 813-819.

[18] Christianson, D., et al., The sex-related difference in serum thyrotropin concentration is androgen mediated. Endocrinology, 1981. 108: p. 529-535.

[19] Sarhan, M.A.A., A.A. Shati, and F.G. Elsaid, Biochemical and molecular studies on the possible influence of the Brassica oleracea and Beta vulgaris extracts to mitigate the effect of food preservatives and food chemical colorants on albino rats. Saudi Journal of Biological Sciences, 2014. 21(4): p. 342-354.
[20] Wang, S., B. Chen, and C. Sun, Regulation effect of curcumin on blood lipids and antioxidation in hyperlipidemia rats. Wei Sheng Yan Jiu., 2000. 29(4): p. 240-242.

[21] Fan, C., et al., Effect of curcumin on the expression of LDL receptor in mouse macrophages. Journal of Ethnopharmacology, 2006. 105(1-2): p. 251-254.

[22] Rhiouania, H., et al., Acute and subchronic toxicity of an aqueous extract of the leaves of Herniaria glabra in rodents. Journal of Ethnopharmacology, 2008. 118: p. 378-386. 